BMJ Open Respiratory Research

\title{
Phenotypic characteristics and asthma severity in an East African cohort of adults and adolescents with asthma: findings from the African severe asthma project
}

Bruce Kirenga (iD , ${ }^{1}$ Jeremiah Chakaya, ${ }^{2}$ Getnet Yimer $^{3}$ George Nyale, ${ }^{4}$ Tewodros Haile, ${ }^{5}$ Winters Muttamba, ${ }^{6}$ Levicatus Mugenyi, ${ }^{6}$ Winceslaus Katagira, ${ }^{7}$ William Worodria, ${ }^{8}$ Hellen Aanyu-Tukamuhebwa, ${ }^{9}$ Njira Lugogo, ${ }^{10}$ Moses Joloba, ${ }^{11}$ Amsalu Bekele, ${ }^{5}$ Fred Makumbi, ${ }^{11}$ Cindy Green, ${ }^{12}$ Corina de Jong, ${ }^{13}$ Moses Kamya, ${ }^{11}$ Thys van der Molen ${ }^{14}$

\section{ABSTRACT}

Rationale The relationship between clinical and biomarker characteristics of asthma and its severity in Africa is not well known.

Methods Using the Expert Panel Report 3, we assessed for asthma severity and its relationship with key phenotypic characteristics in Uganda, Kenya and Ethiopia. The characteristics included adult onset asthma, family history of asthma, exposures (smoking and biomass), comorbidities (HIV, hypertension, obesity, tuberculosis (TB), rhinosinusitis, gastro-oesophageal disease (GERD) and biomarkers (fractional exhaled nitric oxide (FeNO), skin prick test (SPT) and blood eosinophils). We compared these characteristics on the basis of severity and fitted a multivariable logistic regression model to assess the independent association of these characteristics with asthma severity.

Results A total of 1671 patients were enrolled, $70.7 \%$ women, with median age of 40 years. The prevalence of intermittent, mild persistent, moderate persistent and severe persistent asthma was $2.9 \%, 19.9 \%, 42.6 \%$ and $34.6 \%$, respectively. Only $14 \%$ were on inhaled corticosteroids (ICS). Patients with severe persistent asthma had a higher rate of adult onset asthma, smoking, HIV, history of TB, FeNO and absolute eosinophil count but lower rates of GERD, rhinosinusitis and SPT positivity. In the multivariate model, Ethiopian site and a history of GERD remained associated with asthma severity.

Discussion The majority of patients in this cohort presented with moderate to severe persistent asthma and the use of ICS was very low. Improving access to ICS and other inhaled therapies could greatly reduce asthma morbidity in Africa.

employer(s)) 2020. Re-use permitted under CC BY-NC. No commercial re-use. See rights and permissions. Published by BMJ.

For numbered affiliations see end of article.

Correspondence to Dr Bruce Kirenga; brucekirenga@yahoo.co.uk

\section{INTRODUCTION}

Asthma has been defined by the global initiative for asthma (GINA) as a heterogeneous disease usually characterised by chronic

\section{Key messages}

What are the characteristics of asthma in an African cohort including severity, phenotypes, medication exposure and risk factors?

- The prevalence of severe and uncontrolled asthma was very high in a setting where access to conventional therapies such as inhaled corticosteroids is significantly limited.

- In this study, we successfully performed phenotypic characterisation of asthma in an African cohort that included both clinical factors and biomarkers. This is the first report of asthma severity and phenotypes in an East African cohort and this manuscript provides valuable insights into the prevalence of severe asthma, the risk factors for poorly controlled disease and the inflammatory phenotypes of patients in this unique cohort. It highlights the lack of access to therapies that have the potential to significantly impact asthma outcomes in a meaningful way.

airway inflammation and accompanied by a history of recurrent or persistent respiratory symptoms such as wheeze, shortness of breath, chest tightness and cough which varies over time and in intensity, along with variable airflow obstruction. ${ }^{1}$ The disease is estimated to affect 334 million people globally. ${ }^{2}$ The prevalence of asthma in Africa has been estimated as $7.0 \%$ and $9.6 \%$ in rural and urban areas, respectively, and asthma prevalence is rapidly increasing as a result of various factors such as urbanisation, increasing exposures to environmental risk factors and adoption of westernised affluent lifestyles. ${ }^{34}$

Phenotypic characterisation of asthma is critical to understanding the underlying 
pathophysiology and aetiology of disease, development of more efficacious and targeted therapies, asthma prevention and cure. ${ }^{56}$ It has become increasingly evident that tailored therapies are important when managing asthma and that accurately identifying inflammatory and clinical characteristics is essential when determining the most appropriate therapies for patients with asthma of any severity. ${ }^{78}$ This paradigm shift in our approach to the management of asthma patients is highlighted by the latest changes in the GINA strategy that recommend phenotypic characterisation of all asthma patients coupled with identification and management of comorbid disease and risk factor modification. ${ }^{8}$ Targeting inflammatory phenotypes results in improvements in asthma outcomes. ${ }^{6}$ Despite the known advantages of asthma characterisation, very little is known about common asthma characteristics and inflammatory phenotypes in Africa.

Asthma severity has been found to be related to several phenotypic characteristics such as obesity, age, gender, smoking, type of airway inflammation and medication use. ${ }^{9-11}$ As part of the African Severe Asthma Project (ASAP) that was conducted in three African countries (Ethiopia, Kenya and Uganda), we collected extensive data including socio-demographic, environmental and clinical factors (exacerbation rates and healthcare resource utilisation), physiological measures, inflammatory biomarkers and markers of allergic sensitisation in asthma patients presenting to selected chest clinics in the participating countries. The objective of the current analysis was to determine the overall prevalence rates of the studied phenotypic characteristics and asthma severity and to determine the association of the studied characteristics with asthma severity in an African cohort.

\section{METHODS}

\section{Study design}

We performed a cross-sectional analysis of baseline data collected as part of the ASAP. The ASAP project is a prospective, multicentre, cohort study designed to investigate the prevalence, clinical and phenotypic characteristics of severe asthma in Africa. The study sites consisted of three teaching and national referral hospitals in Ethiopia (Black Lion Hospital), Kenya (Kenyatta Hospital) and Uganda (Mulago Hospital).

Extensive socio-demographic, environmental, clinical and physiological characteristic data and inflammatory markers and healthcare resource utilisation rates were collected in this unique cohort. The cohort was comprised of both participants with a pre-existing diagnosis of asthma and those with high-risk symptoms consistent with a high likelihood of asthma who presented to selected chest clinics in the participating countries. Patients with chronic respiratory symptoms such as cough, wheezing, chest pain and shortness of breath who presented to the hospitals were screened for asthma by study medical officers using an asthma screening form (supplemental material, Bruce Kirenga ASAP screening form). Positive asthma at screening was defined as having at least one of the following: (1) >1 characteristic respiratory symptom (wheezing, breathlessness, chest tightness and/or cough), (2) physician-diagnosed asthma, (3) asthma medication use with improvement in symptoms, (4) wheezing in the previous 12 months and (5) pre-bronchodilator (pre-BD) forced expiratory volume $\left(\mathrm{FEV}_{1}\right) /$ forced vital capacity (FVC) ratio $<0.70, \mathrm{FEV}_{1}$ reversibility $>12 \%$ and $200 \mathrm{~mL}$. A pulmonologist confirmed the diagnosis in all patients who screened positive on the asthma form. Additional inclusion criteria included age between 12 and 70 years. We excluded patients with (1) known diagnoses of alternative lung disease such as chronic obstructive pulmonary disease, bronchiectasis, pulmonary fibrosis or tuberculosis (TB), (2) exposure to experimental treatments within the past 3 months and (3) pregnancy by self-reported last menstrual period. Patients with fixed airflow obstruction on spirometry defined as postbronchodilator (post-BD) $\mathrm{FEV}_{1} / \mathrm{FVC}$ ratio $<0.70$ were also excluded. We estimated that a sample size of 1676 patients would provide $90 \%$ information to determine the predictors of severe asthma in the cohort. Eligible patients providing informed consent were consecutively enrolled between August 2016 and May 2018 until the desired sample size was attained.

\section{Study assessments}

We collected baseline information including sociodemographic characteristics, asthma symptom questionnaires, physical examination findings, identified exposures to both outdoor and indoor asthma triggers, smoking history, measured psychosocial stress using questionnaires and noted the presence of comorbidities (eg, allergies and reflux disease). Asthma control was assessed using the asthma control questionnaire (ACQ) ${ }^{12}$ while the National Asthma Education and Prevention Program/ National Heart, Lung and Blood Institute Expert Panel Report (EPR 3) guideline ${ }^{13}$ was used for severity grading. The EPR 3 guideline divides asthma into intermittent and persistent with mild, moderate and severe persistent categories. The EPR 3 guideline also recommends that asthma severity assessments should only be performed on patients who are not currently on asthma therapy.

Spirometry was performed according to American Thoracic Society/European Respiratory Society (ATS/ ERS) guidelines ${ }^{14}$ using a Pneumotrac spirometer with Spirotrac V software (Vitalograph Ltd., Buckingham, United Kingdom). To achieve uniformity, we used the National Health and Nutrition Examination Survey references values for the per cent predicted (\% pred) $\mathrm{FEV}_{1}$ at $1 \mathrm{~s}$ and the \%pred FVC, as no appropriate African reference values were available at the time of the assessment. ${ }^{15}$ Pre-BD spirometry was performed on all patients, and post-BD spirometry was repeated $15 \mathrm{~min}$ after four doses of inhaled salbutamol $(400 \mu \mathrm{g})$ was administered (each dose was separated by $1 \mathrm{~min}$ ) only in patients with $\mathrm{FEV}_{1} /$ FVC ratio $<0.70$. 
Skin prick test (SPT) was performed and interpreted following a standard operating procedure developed based on published international guidelines. ${ }^{16}{ }^{17}$ Briefly after obtaining consent from the patient, setting an emergency tray, confirming the stability and expiry date of the allergens, cleaning the skin with $70 \%$ alcohol, marking sites of application with a skin pen at $2 \mathrm{~cm}$ intervals, we applied one drop of each allergen beside the marks starting from the palm side and working toward the elbow side starting with saline (negative control) and ending with histamine (positive control). Using a sterile lancet, we pierced the skin through the drop. A new lancet was used for each allergen and controls. Reading reactions commenced after $15 \mathrm{~min}$. The size of the weal was measured at the widest diameter and the diameter perpendicular to the widest diameter. An average weal diameter $\geqq 3 \mathrm{~mm}$ indicated a positive reaction. The allergens used in the study were preselected based on their published occurrence in African settings and included house dust mite mix, soya bean, Blomia tropicalis, Bermuda grass (Cynodon dactylon), mould mix IV, Aspergillus fumigatus, dog epithelia (Canis family), cat epithelia (Felis domesticus), German cockroach (Blattella germanica), egg white, cow milk, peanut (Arachys hypogaea) ${ }^{18}$ Allergens were specifically prepared for the project by Immunospec (Pty) Ltd. ${ }^{19}$

Fractional exhaled nitric oxide (FeNO) testing was performed with the NO breath FeNO Monitor according to manufacturer instructions. ${ }^{20}$

Clinical laboratories tests including a complete blood count were performed to determine the levels of circulating peripheral blood eosinophils, with a five-part auto-loader haematology analyser. ${ }^{21}$ Stool-concentrated microscopy was done to look for cysts, ova and parasites, while HIV testing was performed according to participating countries' ministry of health algorithms for HIV testing. Evaluations for ova, parasites and HIV were performed due to a concern that the presence of one of these common diseases could result in peripheral eosinophilia, thus confounding one of our key inflammatory factors of interest.

\section{Definitions}

Adult onset asthma was defined as having a self-reported diagnosis of asthma at $\geq 19$ years of age ${ }^{22}$ Family history of asthma, smoking status, biomass exposure, history of TB, gastro-oesophageal disease (GERD) and rhinosinusitis were all self-reported. HIV testing was performed and the presence of a positive test was based on the presence of viral antigens on confirmatory testing. Hypertension was defined as a blood pressure $\geq 120 / 90 \mathrm{~mm}$ Hg. High eosinophils were defined as having an absolute eosinophil count (AEC) $\geq 300$ cells $/ \mu \mathrm{L}$, high FeNO was defined as FeNO $\geq 35$ ppb and allergic status was defined as having at least one positive allergen on SPT. Uncontrolled asthma was defined as ACQ score $>1.5^{12}$ and asthma exacerbations were defined as an increase in asthma symptoms requiring an unscheduled visit to a health facility or emergency room or resulting in a hospitalisation (ie, due to moderate to severe exacerbations) as recommended by the ATS/ERS guidelines. ${ }^{23} 24$

\section{Statistical analysis}

Descriptive statistics are used to summarise enrolled patient characteristics. Categorical variables are presented as frequencies and percentages for nonmissing data. Continuous variables are reported as the median with IQR 25th and 75th percentiles. The characteristics of interest were compared between severity grades using $\chi^{2}$ and Kruskal-Wallis tests for proportions and medians, respectively. Asthma severity was dichotomised in intermittent-mild persistent and moderate-severe persistent asthma. A multivariate logistic model was fitted to determine independent association of the characteristics with moderate-severe persistent asthma. Akaike information criteria was used for model selection. Predictors that showed multicollinearity using variance inflation factor $>10$ were centred in case of continuous variables or dropped from the final model if they were categorical and non-significant. Variables of scientific importance were retained in the final model even if they were not significant. Results are presented using the OR with 95\% CI. All analyses were done using STATA V.14 software (Stata Corp.). A p value $<0.05$ was considered statistically significant unless otherwise specified.

\section{Ethical considerations}

All patients provided informed consent. Patients $<18$ years of age provided assent while their parents/legal guardians consented.

\section{Patient public involvement}

Neither patients nor the public were involved in the design and conduct of this study.

\section{RESULTS}

\section{Study patients characteristics}

A total of 2242 patients were screened, and 1671 asthma patients were enrolled from August 2016 to May 2018 at the three sites including 419 in Ethiopia, 431 in Kenya and 821 in Uganda. There were 571 excluded patients. The reasons for exclusion included not having asthma (267), contraindication to spirometry (45), declined to give consent (211), age out of range (18) and in experimental treatment trials (17). Overall, the majority of the patients $(70.7 \%)$ were women with a median age of 40 (26-52) years and median body mass index of 24.2 (20.9$28.5) \mathrm{kg} / \mathrm{m}^{2}$ (table 1). The median age at asthma onset was 25 (14-36) years including $19.3 \%$ developing asthma at $\leq 12$ years, $16.0 \%$ at $12-19$ years and $64.7 \%$ at $>20$ years of age. Family history of asthma was reported by $52.0 \%$, smoking by $6.8 \%$ and biomass smoke exposure by $73.0 \%$ of patients (table 1 ). 
Table 1 Study participants baseline characteristics

\begin{tabular}{|c|c|c|c|c|}
\hline \multirow[b]{2}{*}{ Characteristic } & \multirow[b]{2}{*}{$\begin{array}{l}\text { All } \\
(n=1671)\end{array}$} & \multicolumn{3}{|l|}{ By country } \\
\hline & & Uganda $(n=821)$ & $\begin{array}{l}\text { Kenya } \\
(n=431)\end{array}$ & $\begin{array}{l}\text { Ethiopia } \\
(n=419)\end{array}$ \\
\hline Gender: male, n (\%) & $490(29.3)$ & $206(25.1)$ & $109(25.3)$ & $175(41.8)$ \\
\hline Median age (IQR) & $40(26-52)$ & $31(20-44)$ & $42(32-51)$ & $52(42-60)$ \\
\hline $\begin{array}{l}\text { Median age at asthma } \\
\text { diagnosis (IQR) }\end{array}$ & $25(14-36)$ & $20(10-33)$ & $28.5(16-39)$ & $29(22-36)$ \\
\hline $\begin{array}{l}\text { Adult onset asthma ( } \geq 19 \\
\text { years) }\end{array}$ & $1050(62.8)$ & $421(51.3)$ & $283(65.66)$ & $346(82.6)$ \\
\hline $\begin{array}{l}\text { Family history of asthma, } n \\
(\%)\end{array}$ & $869(52.0)$ & $491(59.8)$ & $229(53.1)$ & $149(35.6)$ \\
\hline $\begin{array}{l}\text { Smoking (current/former), } \mathrm{n} \\
(\%)\end{array}$ & $113(6.8)$ & $39(4.8)$ & $38(8.8)$ & $36(8.6)$ \\
\hline $\begin{array}{l}\text { Secondhand smoke exposure, } \\
n(\%)\end{array}$ & $141(8.4)$ & $51(6.2)$ & $67(15.6)$ & $23(5.5)$ \\
\hline Biomass exposure, $\mathrm{n}(\%)$ & $1221(73.1)$ & $643(78.3)$ & $274(63.6)$ & $304(72.6)$ \\
\hline Cough, n (\%) & $736(44.1)$ & $360(43.9)$ & $187(43.4)$ & $189(45.1)$ \\
\hline Wheeze, n (\%) & $664(39.7)$ & $319(38.9)$ & $187(43.4)$ & $158(37.7)$ \\
\hline Median BMI kg/m² (IQR) & $24.2(20.9-28.5)$ & $23.7(20.4-28.4)$ & $26.1(22.1-30.7)$ & $23.8(21.1-26.8)$ \\
\hline Pre-BD FVC\%, median (IQR) & $94(76-109)$ & $101(84-115)$ & $89(74-101)$ & $2.3(1.7-2.9)$ \\
\hline Pre-BD FEV ${ }_{1} \%$, median (IQR) & $76(53-95)$ & $87(65-103)$ & $76(58-90)$ & $53(40-69)$ \\
\hline $\begin{array}{l}\text { Pre-BD FEV } / \text { /FVC ratio, } \\
\text { median (IQR) }\end{array}$ & $0.7(0.6-0.8)$ & $0.8(0.7-0.8)$ & $0.7(0.6-0.8)$ & $0.5(0.4-0.6)$ \\
\hline $\begin{array}{l}\text { Bronchodilator reversibility, } \\
\text { median (IQR) }\end{array}$ & $19(12-30.8) n=1077$ & $20.5(15.0-31.6) n=268$ & $9(4-19) n=408$ & $24.9(17.3-41.9) n=401$ \\
\hline Ova/cysts & $1(0.2)$ & $1(0.2)$ & $0(0.0)$ & $0(0.0)$ \\
\hline $\begin{array}{l}\text { Uncontrolled asthma (ACQ } \\
>1.5)\end{array}$ & 957 (57.3) & $427(52.0)$ & $223(51.7)$ & 307 (73.3) \\
\hline $\begin{array}{l}\text { Number of exacerbations in } \\
\text { past year, median (IQR) }\end{array}$ & $3(1-10)$ & $4(2-10)$ & $3(0-10)$ & $2(0-8)$ \\
\hline $\begin{array}{l}\text { Number of courses of oral } \\
\text { steroids prescribed }\end{array}$ & $1(0-4)$ & $1(0-4)$ & $0(0-2)$ & $1(0-5)$ \\
\hline $\begin{array}{l}\text { Three or more exacerbations } \\
\text { in the past year, } n(\%)\end{array}$ & $984(59.1)$ & $566(68.9)$ & $223(52.0)$ & $195(47.0)$ \\
\hline $\begin{array}{l}\text { Any hospitalisation in past } \\
\text { year, } n(\%)\end{array}$ & $358(21.4)$ & $204(24.9)$ & $51(11.9)$ & $103(24.6)$ \\
\hline On any ICS & $230(14.0)$ & $65(17.3)$ & $89(12.7)$ & 76 (13.3) \\
\hline Not on any asthma medication & $206(12.5)$ & $73(19.5)$ & 87 (12.6) & $46(8.1)$ \\
\hline
\end{tabular}

$\mathrm{ACQ}$, asthma control questionnaire; BMI, body mass index; FEV, forced expiratory volume; FVC, forced vital capacity; ICS, inhaled corticosteroids; pre-BD, pre-bronchodilator.

Respiratory symptoms, asthma control, exacerbations, lung function and medication utilisation

Forty-four per cent of the patients reported a cough, while $39.7 \%$ reported history of a wheeze. The median number of exacerbations in the year prior to enrolment was 3 (IQR: 1-10). Fifty-nine per cent of the population experienced $\geq 3$ exacerbations and $21.4 \%$ had had at least one hospitalisation due to asthma in the year before enrolment. Of note, $57.3 \%$ of the population had uncontrolled asthma as defined by an ACQ score $>1.5$. The median pre-BD \%pred FVC was 94 (76-109)\%, median $\%$ pred $\mathrm{FEV}_{1}$ was $76(53-95) \%$ and the $\mathrm{FEV}_{1} / \mathrm{FVC}$ ratio was $0.70(0.6-0.8)$. Only patients with an $\mathrm{FEV}_{1} / \mathrm{FVC}$ ratio had reversibility testing performed and we identified a median $\mathrm{FEV}_{1}$ per cent reversibility of 19.0 (12-30.8)\% (table 1). Rhinosinusitis, obesity and GERD were the most prevalent comorbid conditions (table 2).

Medications patients were using at the time of enrolment are shown in table 3. Twenty-four per cent of the enrolled patients were on salbutamol tablets, $17.1 \%$ aminophylline tablets, $13.2 \%$ aminophylline injections, $37.3 \%$ oral and $11.4 \%$ injectable corticosteroids, only $14.1 \%$ were on an inhaled corticosteroid (ICS) with an additional $16.5 \%$ using combination ICS/long-acting 
Table 2 Asthma characteristics comorbid conditions and inflammatory markers on the basis of severity

\begin{tabular}{|c|c|c|c|c|c|}
\hline & $\begin{array}{l}\text { Overall } \\
(n=1649)\end{array}$ & $\begin{array}{l}\text { Intermittent/mild } \\
\text { persistent } \\
(\mathrm{n}=375)\end{array}$ & $\begin{array}{l}\text { Moderate } \\
\text { persistent } \\
(\mathrm{n}=703)\end{array}$ & $\begin{array}{l}\text { Severe } \\
\text { persistent } \\
(n=571)\end{array}$ & $P$ value \\
\hline Country & & & & & $<0.001$ \\
\hline Uganda, $n(\%)$ & $819(49.7)$ & $231(61.6)$ & $411(58.5)$ & $177(31.0)$ & \\
\hline Kenya, $\mathrm{n}(\%)$ & $424(25.7)$ & $108(28.8)$ & $159(22.6)$ & $157(27.5)$ & \\
\hline Ethiopia, n(\%) & 406 (24.6) & $36(9.6)$ & $133(18.9)$ & $237(41.5)$ & \\
\hline $\begin{array}{l}\text { Adult onset asthma (onset } \geq 19 \text { years), } \\
\mathrm{n}(\%)\end{array}$ & $1034(62.7)$ & $202(53.9)$ & $433(61.6)$ & $399(69.9)$ & $<0.001$ \\
\hline \multicolumn{6}{|l|}{ Age in years (median, IQR) } \\
\hline Family history of asthma, $\mathrm{n}(\%)$ & 861 (52.2) & $211(56.3)$ & $366(52.1)$ & $284(49.7)$ & 0.131 \\
\hline Smoking (current/former), n (\%) & $111(6.7)$ & $16(4.3)$ & $37(5.3)$ & $58(10.2)$ & $<0.001$ \\
\hline Biomass smoke, $n(\%)$ & $1205(73.1)$ & $271(72.3)$ & $527(75.0)$ & 407 (71.3) & 0.324 \\
\hline \multicolumn{6}{|l|}{ Comorbidities, n (\%) } \\
\hline HIV & $63(3.8)$ & $13(3.5)$ & $18(2.6)$ & $32(5.6)$ & 0.017 \\
\hline Hypertension & $193(11.7)$ & $34(9.1)$ & $80(11.4)$ & 79 (13.8) & 0.078 \\
\hline Obesity & $316(19.2)$ & $70(18.7)$ & $138(19.6)$ & $108(18.9)$ & 0.945 \\
\hline Tuberculosis & $19(1.2)$ & $5(1.3)$ & $3(0.4)$ & $11(1.9)$ & 0.032 \\
\hline GERD & $288(17.5)$ & $58(15.5)$ & $143(20.3)$ & $87(15.2)$ & 0.030 \\
\hline Rhinosinusitis & $370(22.4)$ & $103(27.5)$ & $174(24.8)$ & $93(16.3)$ & $<0.001$ \\
\hline SPT, N & 1649 & 375 & 703 & 571 & \\
\hline At least one positive SPT, \% & 67.3 & 69.9 & 69.3 & 63.1 & 0.029 \\
\hline 2-3 positive SPT, \% & 40.7 & 45.3 & 43.1 & 34.7 & 0.002 \\
\hline FeNO ppb, N & 1334 & 307 & 583 & 444 & \\
\hline Median (IQR) & $25(12-48)$ & $22(9-40)$ & $22(11-44)$ & $32(16-57)$ & $<0.001$ \\
\hline $\mathrm{FeNO} \geq 35 \mathrm{ppb}, \%$ & 37.4 & 31.9 & 34.5 & 45.1 & $<0.001$ \\
\hline AEC, $N$ & 1511 & 356 & 649 & 506 & \\
\hline Median (IQR) & $270(140-510)$ & $240(120-415)$ & $270(140-510)$ & $305(160-560)$ & 0.001 \\
\hline $\mathrm{AEC}>300$ cells $/ \mu \mathrm{L}, \%$ & 45.1 & 38.2 & 45.0 & 50.0 & 0.003 \\
\hline
\end{tabular}

AEC, absolute eosinophil count; FENO, fractional exhaled nitric oxide; GERD, gastro-oesophageal disease; SPT, skin prick test.

beta agonist therapies (table 3). Overall, $12 \%$ were not taking any medications for asthma. Severe asthma was associated with increased salbutamol inhaler and nebuliser use, injectable steroid, leukotrienes and theophylline use. The use of oral and injectable steroids was high regardless of asthma severity with one-third of all patients receiving oral steroids.

\section{Inflammatory biomarkers}

The prevalence of an elevated FeNO level $>35 \mathrm{ppb}$ was $37.4 \%$ with a median FeNO level of 25 (12-48). The median eosinophil count was 270 (140-510) cells/ $\mu \mathrm{L}$ with $45 \%$ of patients having an eosinophil count $>300$ cells $/ \mu \mathrm{L}$ (table 2 ). Two-thirds of the cohort demonstrated allergic sensitisation with at least one positive allergen on SPT. Individual allergen reactivity by country is presented in online supplementary table 1 . We examined the prevalence of overlapping inflammatory biomarkers and noted that $16.3 \%$ of the population had three overlapping markers. Of note, $16.4 \%$ of the cohort had overlapping eosinophils and one positive SPT and $11.1 \%$ had both positive SPT and high FeNO. Lastly, 5\% of the cohort had overlapping high FeNO and eosinophils (figure 1). Interestingly, only $8.9 \%$ of patients had no positive inflammatory markers.

\section{Asthma severity and selected phenotypic characteristics}

The prevalence of mild intermittent, mild, moderate and severe persistent asthma was 2.9\%, 19.9\%, 42.6\% and $34.6 \%$, respectively. Patients with severe persistent asthma had a higher rate of adult onset asthma compared with those with moderate persistent and mild intermittent/ persistent disease $(69.9 \%$ vs $61.6 \%$ vs $53.9 \%, \mathrm{p} \leq 0.001)$; higher smoking rate $(10.2 \%$ vs $5.3 \%$ vs $4.3 \%, \mathrm{p} \leq 0.001)$; HIV-positive status $(5.6 \%$ vs $2.6 \%$ vs $3.5 \%, \mathrm{p}=0.017)$, history of TB $(1.9 \%$ vs $0.4 \%$ vs $1.3 \%, \mathrm{p}=0.032)$, median FeNO (32 vs 22 vs 22, p $\leq 0.001)$ and median AEC (370 vs 270 vs $240, p=0.001)$. Conversely those with severe 
Table 3 Asthma medications by severity

\begin{tabular}{|c|c|c|c|c|c|}
\hline & $\begin{array}{l}\text { Overall } \\
\mathrm{n}(\%)\end{array}$ & $\begin{array}{l}\text { Mild intermittent/ } \\
\text { persistent } \\
\mathrm{n}(\%)\end{array}$ & $\begin{array}{l}\text { Moderate } \\
\text { persistent } \\
\mathrm{n}(\%)\end{array}$ & $\begin{array}{l}\text { Severe } \\
\text { persistent n (\%) }\end{array}$ & $P$ value \\
\hline & $n=1649$ & $\mathrm{n}=375$ & $n=703$ & $n=571$ & \\
\hline \multicolumn{6}{|l|}{ Short-acting bronchodilators } \\
\hline Salbutamol tablets/syrup & $400(24.3)$ & $75(20.0)$ & $198(28.2)$ & $127(22.2)$ & 0.005 \\
\hline Salbutamol inhaler & $894(54.2)$ & $186(49.6)$ & $347(49.4)$ & $361(63.2)$ & $<0.001$ \\
\hline Salbutamol/ipratropium & $9(0.5)$ & & & & \\
\hline Nebulised salbutamol & $169(10.1)$ & $32(8.5)$ & $59(8.4)$ & $78(13.7)$ & 0.005 \\
\hline Nebulised salbutamol/ipratropium & $33(2.0)$ & $8(2.1)$ & $14(2.0)$ & $11(1.9)$ & 0.963 \\
\hline \multicolumn{6}{|l|}{ Corticosteroids } \\
\hline Nebulised steroids & $26(1.6)$ & $2(0.5)$ & $13(1.9)$ & $11(1.9)$ & 0.192 \\
\hline Oral steroids & $621(37.7)$ & $126(33.6)$ & $280(39.8)$ & $215(37.7)$ & 0.185 \\
\hline Injectable steroids & $191(11.6)$ & $29(7.7)$ & $92(13.1)$ & $70(12.3)$ & 0.033 \\
\hline Inhaled steroids & $230(14.0)$ & 65 (17.3) & $89(12.7)$ & $76(13.3)$ & 0.069 \\
\hline \multicolumn{6}{|l|}{$\begin{array}{l}\text { Combination inhalers (corticosteroids-long- } \\
\text { acting beta agonists) }\end{array}$} \\
\hline Combination inhalers & $274(16.6)$ & $56(14.9)$ & $113(16.1)$ & $105(18.4)$ & 0.394 \\
\hline \multicolumn{6}{|l|}{ Leukotriene modifiers } \\
\hline Leukotriene modifiers & $128(7.8)$ & $39(10.4)$ & $57(8.1)$ & $32(5.6)$ & 0.018 \\
\hline \multicolumn{6}{|l|}{ Other } \\
\hline Theophylline/aminophylline tablets & $284(17.2)$ & $40(10.7)$ & $120(17.1)$ & $124(21.7)$ & $<0.001$ \\
\hline Theophylline/aminophylline injections & $219(13.3)$ & $30(8.0)$ & $94(13.4)$ & $95(16.6)$ & 0.001 \\
\hline No current asthma medication & $206(12.5)$ & 73 (19.5) & 87 (12.6) & $46(8.1)$ & $<0.001$ \\
\hline
\end{tabular}

Data presented as count (percentage).

persistent asthma had lower rates of GERD compared with moderate persistent and mild intermittent/persistent patients $(15.2 \%$ vs $20.3 \%$ vs $15.5 \%, \mathrm{p}=0.030)$, rhinosinusitis $(16.3 \%$ vs $24.8 \%$ vs $27.5 \%, \mathrm{p} \leq 0.001)$ and SPT positivity $(63.1 \%$ vs $69.9 \%$ vs $69.9 \%, p=0.029)$ (table 2$)$. In a multivariate model including these characteristics, current use of ICS and country, the only characteristics

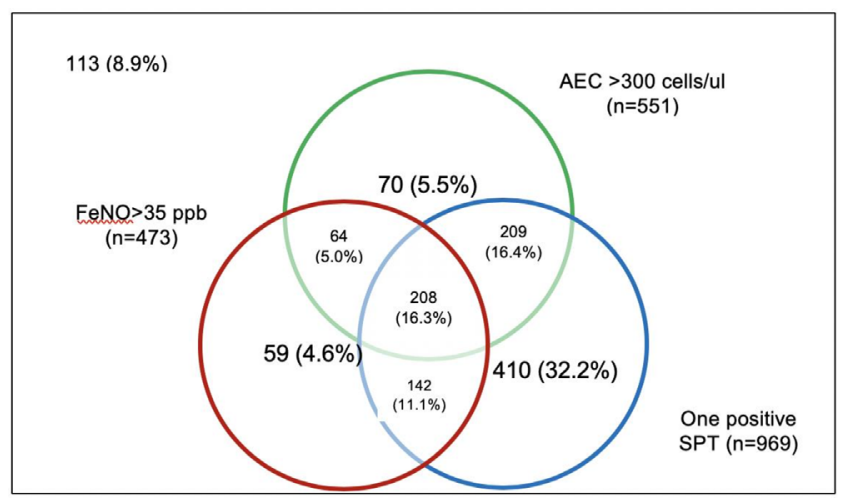

Figure 1 Venn diagram showing overlap between high AEC, high FeNo and $\geq 1$ positive SPT in patients with all three variables measured $(n=1275)$. Of note, $8.9 \%$ of the patients did not demonstrate positivity on any of the variables. AEC, absoluteeosinophil count; FeNO, fractional exhaled nitric oxide; SPT, skinprick test. that remained significantly associated with moderate to severe persistent asthma were being from the Ethiopian site-adjusted OR $(95 \% \mathrm{CI}) 4.58 \quad(2.46-8.51, \mathrm{p} \leq 0.001)$, GERD $1.78(1.20-2.65, \mathrm{p}=0.004)$ and current use of ICS $0.57(0.38-0.86,0.008)$ (table 4$)$.

\section{DISCUSSION}

The ASAP cohort provides a unique opportunity to understand both the prevalence and characteristics of severe asthma in Eastern Africa. Little is known about asthma in Africa despite the high morbidity and mortality associated with this disease. The study enrolled a large number of patients and successfully completed phenotypic characterisation in a resource limited setting. Several important differences between asthma in this cohort and others around the world were identified. The ASAP cohort had a higher rate of adult onset asthma patients $(62.8 \%)$ as compared with $24 \%$ of a cohort in the Netherlands. ${ }^{22}$ Factors that increase the risk of adult onset asthma include female gender, obesity, occupational exposures, exposure to cleaning agents, air pollution, smoking and respiratory infections. ${ }^{25-27}$ We postulate that the higher prevalence of adult onset asthma in this cohort may be related to environmental exposures with a large proportion of the patients being exposed to indoor and outdoor air pollution. We also recognise that delays in the initial 
Table 4 Association between moderate-severe persistent asthma and selected phenotypic characteristics at multivariate analysis

\begin{tabular}{|c|c|c|c|c|}
\hline \multirow[b]{2}{*}{ Factor } & \multicolumn{2}{|c|}{ Unadjusted estimates } & \multicolumn{2}{|l|}{ Adjusted estimates } \\
\hline & $\begin{array}{l}\text { OR } \\
(95 \% \mathrm{Cl})\end{array}$ & $P$ value & $\begin{array}{l}\text { OR } \\
(95 \% \mathrm{Cl})\end{array}$ & $P$ value \\
\hline \multicolumn{5}{|l|}{ Country } \\
\hline Uganda & Reference & & Reference & \\
\hline Kenya & $1.15(0.88$ to 1.50$)$ & 0.305 & $1.04(0.72$ to 1.49$)$ & 0.842 \\
\hline Ethiopia & 4.04 (2.78 to 5.87$)$ & $<0.001$ & 4.58 (2.46 to 8.51$)$ & $<0.001$ \\
\hline Adult onset asthma (onset $>19$ years) & 1.65 (1.30 to 2.10$)$ & $<0.001$ & $1.24(0.92$ to 1.67$)$ & 0.162 \\
\hline Family history of asthma & 0.80 (0.63 to 1.01$)$ & 0.058 & $0.95(0.71$ to 1.26$)$ & 0.702 \\
\hline Smoking (current/former) & $1.81(1.05$ to 3.11$)$ & 0.033 & & \\
\hline Biomass exposure & $1.05(0.81$ to 1.36$)$ & 0.733 & $1.02(0.74$ to 1.41$)$ & 0.702 \\
\hline HIV & $1.14(0.61$ to 2.12$)$ & 0.684 & & \\
\hline Tuberculosis history & $0.82(0.29$ to 2.30$)$ & 0.709 & & \\
\hline Hypertension & $1.43(0.97$ to 2.11$)$ & 0.072 & & \\
\hline Obesity & 1.05 (0.78 to 1.40$)$ & 0.767 & 1.12 (0.78 to 1.61$)$ & 0.533 \\
\hline GERD & $1.20(0.88$ to 1.65$)$ & 0.247 & $1.78(1.20$ to 2.65$)$ & 0.004 \\
\hline Rhinosinusitis & $0.70(0.54$ to 0.91$)$ & 0.008 & & \\
\hline At least one positive SPT, \% & $0.86(0.67$ to 1.10$)$ & 0.220 & & \\
\hline FeNO $\geq 35$ ppb, $\%$ & 1.37 (1.04 to 1.79$)$ & 0.024 & 1.17 (0.85 to 1.60$)$ & 0.329 \\
\hline AEC $>300$ cells $/ \mu \mathrm{L}, \%$ & 1.45 (1.13 to 1.84$)$ & 0.003 & $1.09(0.81$ to 1.46$)$ & 0.571 \\
\hline
\end{tabular}

AEC, absolute eosinophil count; FeNO, fractional exhaled nitric oxide; GERD, gastro-oesophageal disease; SPT, skin prick test.

diagnosis of asthma due to poor access to medical care may contribute to a falsely elevated incidence of adult onset asthma. Notably, the prevalence of obesity in this cohort was very low which is in sharp contrast to most adult onset asthma cohorts, therefore obesity is not likely to explain the higher prevalence of adult onset asthma noted in the ASAP cohort. ${ }^{28-30}$

The majority of the patients in the cohort had moderate and severe persistent asthma with a high level of poor asthma control and significant morbidity associated with increased healthcare utilisation. The cohort was recruited from three tertiary care centres and therefore this sample may not be representative of the rates of severe disease in the general population. Comparatively, a European Community Respiratory Health Survey found intermittent, mild persistent, moderate persistent and severe persistent asthma rates of $31.7 \%, 13.5 \%, 14 \%$ and $40.7 \%$, respectively. ${ }^{31}$ These rates are significantly lower than those in our cohort. Notably, since the use of medications for asthma was very low in our cohort we had the opportunity to determine severity in the absence of confounding therapies as recommended by the EPR 3 guidelines which is a strength of this study. ${ }^{32}$ In addition, it is not suprising that we found higher severity rates, since few patients were using controller medications; therefore, severe forms of asthma observed could be categorised as severe untreated asthma ${ }^{33}$ rather than treatment-resistant asthma which occurs when adequate controller therapy has been used. ${ }^{34}$ We cannot however discount the possibility that the prevalence of more severe disease is a result of other factors such as race given the high prevalence of severe asthma in blacks of African descent in other countries. ${ }^{35}$ Patients in this study had high rates of asthma exacerbations with $59.1 \%$ reporting $\geq 3$ exacerbations in the past year. The rates of exacerbations observed are much higher than observed in developed countries, most likely resulting from untreated or undertreated disease. The factors associated with severe asthma include tobacco use, HIV, a history of TB, GERD, rhinosinusitis, elevated FeNO, AEC and allergic sensitisation. Use of ICS was associated with a lower odd ratio of having severe asthma. Interestingly, although inflammatory markers were more prevalent in severe asthma, the impact of these markers on asthma severity was not significant in our multivariate models. Patients from Ethiopia had a higher OR of having severe disease.

Adult onset asthma is associated with a high prevalence of allergic and eosinophilic inflammation. We demonstrate similar findings with a high prevalence of allergic and eosinophilic inflammation that is notably most prominent in severe asthma which was associated with elevated eosinophils and FeNO levels. Interestingly, the prevalence of HIV and the presence of parasitic infection was very low in this cohort, thus ensuring that these potential confounders of eosinophilia did not impact the high prevalence rates noted in the cohort. ${ }^{36}$ The high rates of allergic sensitisation may be a result of geographical location, as the study sites were in large urban areas 
where exposure to allergens is higher. Rates of allergy and asthma are known to be higher in urban areas. ${ }^{4}$

There was discordance between the high prevalence of severe disease and the use of maintenance therapies for asthma. Significant disparities exist in asthma care in the region with a very small proportion of patients receiving therapy with ICS and anti-inflammatory combination therapies. Most of the patients received bronchodilator therapy and systemic corticosteroids (SCS) which are likely the most economically attainable medications for asthma. None of the patients were treated with biologicals or targeted therapies for asthma. The GINA strategy 2019 demonstrated the urgent need for a paradigm shift in the management of asthma with a particular focus on the negative consequences of shortacting beta agonist (SABA) monotherapy in asthma. ${ }^{8}$ The patients in our cohort are at an unacceptably high risk of the poor outcomes including death that are associated with overuse of SABA. More importantly, the toxicities associated with SCS use cannot be understated ${ }^{37}$ and the long-term consequences and economic burden of non-communicable diseases that occur at a high rate in patients exposed to SCS will be significant.

Our study had limitations including the lack of sputum cell counts, specific IgE to determine allergic sensitisation and total IgE measurements. Blood eosinophils are increasingly accepted as surrogate markers of inflammation in asthma and they accurately identify responders to targeted therapies ${ }^{38-41}$ and were therefore selected for this study. Furthermore, sputum is challenging to obtain and is not easily generalisable to non-academic settings, thus our focus is on blood eosinophils. Other limitations of the study are the study being tertiary hospital based which could mean that patients recruited may not represent general population patients, and using African American spirometry reference ranges which may not be appropriate for East African Americans.

The ASAP study highlights the disparities that exist in asthma care in Africa. Despite a high prevalence of patients with severe asthma and the associated significant morbidity caused by the disease, access to medications is limited. This highlights the urgent need for intervention and new strategies that can close the gap and improve the lives of many patients with asthma. As the focus of international organisations moves towards non-communicable diseases, the burden of respiratory disease such as asthma must be highlighted and addressed.

\section{Author affiliations}

${ }^{1}$ College of Health Sciences, Makerere University, Kampala, Uganda

${ }^{2}$ Kenya Association of Physicians against TB and Lung Diseases (KAPTLD), Nairobi, Kenya

${ }^{3}$ College of Health Sciences, Addis Ababa University, Addis Ababa, Ethiopia

${ }^{4}$ Department of Medicine, Kenyatta National Hospital, Nairobi, Kenya

${ }^{5}$ College of Health Sciences, Addis Ababa University, Addis Ababa, Ethiopia

${ }^{6}$ Lung Institute, Makerere University College of Health Sciences, Kampala, Uganda

${ }^{7}$ Lung Institute, Makerere University College of Health Sciences, Kampala, Uganda
${ }^{8}$ Mulago National Referral Hospital, Uganda Ministry of Health, Kampala, Uganda

${ }^{9}$ Mulago National Referral Hospital, Uganda Ministry of Health, Kampala, Uganda

${ }^{10}$ Internal Medicine, University of Michigan, Ann Arbor, Michigan, USA

${ }^{11}$ College of Health Sciences, Makerere University, Kampala, Uganda

${ }^{12}$ Medicine, Duke University School of Medicine, Durham, North Carolina, USA

${ }^{13}$ Department of General Practice, University of Groningen, University Medical Center Groningen, Groningen, The Netherlands

${ }^{14}$ University Medical Center Groningen (UMCG), University of Groningen, Groningen, Netherlands

Acknowledgements We thank all patients who accepted to participate in ASAP. We would like to acknowledge the tireless dedication of all clinicians who recruited and followed patients in ASAP. We also thank all data officers led by the Data Manager Mr Rogers Sekibira, and the data quality assurance team.

Contributors BK conceived the initial idea of the ASAP project and BK, TvdM, JC, GY, MK, MJ and CdJ designed the study. WM, WW, HA-T, WK, GN, GY, JC, AB, TH and BK participated in data acquisition. CdJ coordinated data quality control. BK wrote the original draft of the manuscript. BK, NL, FM, CG and LM conducted the data analysis. All authors contributed to the drafting and finalisation of the manuscript.

Funding The study was funded by a project grant from the GSK Africa NonCommunicable Disease Open Lab (Project number: 8019). The funder provided in-kind scientific and statistical support in the study design but had no role in data collection, analysis or decision to publish. Authors retained control of the final content of the publication.

Competing interests None declared.

Patient consent for publication Not required.

Ethics approval Overall ethics approval was obtained from the Mulago Hospital research and ethics committee (MHREC 875). and from local ethics committees in each country.

Provenance and peer review Not commissioned; externally peer reviewed.

Data availability statement Data are available upon reasonable request. Data used in this manuscript is available in hard paper copy and soft copy data files at Makerere University Lung Institute and each participating institution.

Open access This is an open access article distributed in accordance with the Creative Commons Attribution Non Commercial (CC BY-NC 4.0) license, which permits others to distribute, remix, adapt, build upon this work non-commercially, and license their derivative works on different terms, provided the original work is properly cited, appropriate credit is given, any changes made indicated, and the use is non-commercial. See: http://creativecommons.org/licenses/by-nc/4.0/.

ORCID iD

Bruce Kirenga http://orcid.org/0000-0002-2023-2840

\section{REFERENCES}

1 Asher MI, Montefort S, Björkstén B, et al. Worldwide time trends in the prevalence of symptoms of asthma, allergic rhinoconjunctivitis, and eczema in childhood: Isaac phases one and three repeat multicountry cross-sectional surveys. The Lancet 2006;368:733-43.

2 To T, Stanojevic S, Moores G, et al. Global asthma prevalence in adults: findings from the cross-sectional World health survey. BMC Public Health 2012;12:204.

3 Adeloye D, Chan KY, Rudan I, et al. An estimate of asthma prevalence in Africa: a systematic analysis. Croat Med J 2013;54:519-31.

4 Weinberg EG. Urbanization and childhood asthma: an African perspective. J Allergy Clin Immunol 2000;105:224-31.

5 Wenzel SE. Asthma phenotypes: the evolution from clinical to molecular approaches. Nat Med 2012;18:716-25.

6 Fajt ML, Wenzel SE. Asthma phenotypes and the use of biologic medications in asthma and allergic disease: the next steps toward personalized care. J Allergy Clin Immunol 2015;135:299-310.

7 Lazarus SC, Krishnan JA, King TS, et al. Mometasone or tiotropium in mild asthma with a low sputum eosinophil level. $N$ Engl J Med 2019;380:2009-19.

8 Strategy G. Global initiative for asthma; global strategy for asthma management and prevention, 2017, 2019. Available: www. ginasthma.org

9 Ställberg B, Lisspers K, Hasselgren M, et al. Factors related to the level of severity of asthma in primary care. Respir Med 2007;101:2076-83. 
10 Varraso R, Siroux V, Maccario J, et al. Asthma severity is associated with body mass index and early menarche in women. Am J Respir Crit Care Med 2005;171:334-9.

11 Shim CS, Williams MH, MHJAoim W. Relationship of wheezing to the severity of obstruction in asthma. Arch Intern Med 1983:143:890-2.

12 Juniper EF, O'Byrne PM, Guyatt GH, et al. Development and validation of a questionnaire to measure asthma control. Eur Respir $J$ 1999;14:902-7.

13 National Heart L, Institute B. Expert panel report 3 (EPR3): guidelines for the diagnosis and management of asthma, 2007. Available: http://www nhlbi nih gov/guidelines/asthma/

14 Miller MR, Hankinson J, Brusasco V, et al. Standardisation of spirometry. Eur Respir J 2005;26:319-38.

15 Ford ES. The epidemiology of obesity and asthma. J Allergy Clin Immunol 2005;115:897-909.

16 Dreborg S. The skin prick test in the diagnosis of atopic allergy. J Am Acad Dermatol 1989;21:820-1.

17 Heinzerling L, Mari A, Bergmann K-C, et al. The skin prick testEuropean standards. Clin Transl Allergy 2013;3:3.

18 Deschildre A. [Allergens causing respiratory allergy: the aeroallergens]. Arch Pediatr 1999;6 Suppl 1:48S-54.

19 SkinPrickTest. Available: https://www.inmunotek.com/en/ immunospec/

20 NoBreath FeNO monitor. Available: https://www.bedfont.com/shop/ nobreath/nobreath-feno-monitor

21 BeckmanCoulter. Available: https://www.beckmancoulter.com

22 Amelink M, de Nijs SB, de Groot JC, et al. Three phenotypes of adult-onset asthma. Allergy 2013;68:674-80.

23 Schatz M, Meckley LM, Kim M, et al. Asthma exacerbation rates in adults are unchanged over a 5-year period despite high-intensity therapy. J Allergy Clin Immunol 2014;2:570-4.

24 Reddel HK, Taylor DR, Bateman ED, et al. An official American thoracic Society/European respiratory Society statement: asthma control and exacerbations: standardizing endpoints for clinical asthma trials and clinical practice. Am J Respir Crit Care Med 2009;180:59-99.

25 LeVan TD, Koh W-P, Lee H-P, et al. Vapor, dust, and smoke exposure in relation to adult-onset asthma and chronic respiratory symptoms: the Singapore Chinese Health study. Am J Epidemiol 2006;163:1118-28.

26 Jamrozik E, Knuiman MW, James A, et al. Risk factors for adult-onset asthma: a 14-year longitudinal study. Respirology 2009;14:814-21.

27 Jarjour NN, Erzurum SC, Bleecker ER, et al. Severe asthma: lessons learned from the National heart, lung, and blood Institute severe asthma research program. Am J Respir Crit Care Med 2012;185:356-62.
28 Holguin F, Fitzpatrick A, Obesity FA. Obesity, asthma, and oxidative stress. J Appl Physiol 2010;108:754-9.

29 Holguin F, Rojas M, Brown LA, et al. Airway and plasma leptin and adiponectin in lean and obese asthmatics and controls. J Asthma $2011 ; 48: 217-23$.

30 Moore WC, Meyers DA, Wenzel SE, et al. Identification of asthma phenotypes using cluster analysis in the severe asthma research program. Am J Respir Crit Care Med 2010;181:315-23.

31 Raherison C, Janson C, Jarvis D, et al. Evolution of asthma severity in a cohort of young adults: is there any gender difference? PLOS One 2009;4:e7146.

$32 \mathrm{NHLBI}$. Guidelines for the diagnosis and management of asthma (2007) United States United States Department of Health and Human Services; National Heart, Lung, Blood Institute (NHLBI) and National Asthma Education and Prevention Program; Expert Panel Report; 2007.

33 Bousquet J, Mantzouranis E, Cruz AA, et al. Uniform definition of asthma severity, control, and exacerbations: document presented for the world Health organization consultation on severe asthma. $J$ Allergy Clin Immunol 2010;126:926-38.

34 Chung KF, Wenzel SE, Brozek JL, et al. International ERS/ATS guidelines on definition, evaluation and treatment of severe asthma. Eur Respir J 2014;43:343-73.

35 Lester LA, Rich SS, Blumenthal MN, et al. Ethnic differences in asthma and associated phenotypes: collaborative study on the genetics of asthma. J Allergy Clin Immunol 2001;108:357-62.

36 Amoah AS, Boakye DA, Yazdanbakhsh M, et al. Influence of parasitic worm infections on allergy diagnosis in sub-Saharan Africa. Curr Allergy Asthma Rep 2017;17:65.

37 Price DB, Trudo F, Voorham J, et al. Adverse outcomes from initiation of systemic corticosteroids for asthma: long-term observational study. J Asthma Allergy 2018;11:193-204.

38 Bleecker ER, FitzGerald JM, Chanez P, et al. Efficacy and safety of benralizumab for patients with severe asthma uncontrolled with high-dosage inhaled corticosteroids and long-acting $\beta 2$-agonists (SIROCCO): a randomised, multicentre, placebo-controlled phase 3 trial. The Lancet 2016;388:2115-27.

39 FitzGerald JM, Bleecker ER, Menzies-Gow A, et al. Predictors of enhanced response with benralizumab for patients with severe asthma: pooled analysis of the SIROCCO and CALIMA studies. Lancet Respir Med 2018:6:51-64.

40 Ortega $\mathrm{H}$, Li H, Suruki R, et al. Cluster analysis and characterization of response to mepolizumab. A step closer to personalized medicine for patients with severe asthma. Ann Am Thorac Soc 2014;11:1011-7.

41 Pavord ID, Korn S, Howarth P, et al. Mepolizumab for severe eosinophilic asthma (DREAM): a multicentre, double-blind, placebocontrolled trial. The Lancet 2012;380:651-9. 